\title{
Steady-state Canopy Gas Exchange: System Design and Operation
}

\author{
Bruce Bugbee \\ Plants, Soils, and Biometerology Department, Utah State University, Logan, UT 84322-4820
}

\begin{abstract}
Commercial growth chambers can be altered to measure wholeplant and canopy $\mathrm{CO}_{2}$ fluxes, and the modifications greatly improve traditional growth studies. Measurement of $\mathrm{CO}_{2}$ fluxes can provide a nondestructive measurement of daily growth, as well as photosynthetic and respiratory efficiency. Recent advances in instrumentation have significantly improved photosynthesis measurements, and the techniques have been refined in small-scale (single-leaf), gas-exchange systems. Although whole-plant applications in larger growth chambers have developed slowly, our knowledge has increased dramatically in the last decade. For example, two major books on controlled environments in the late 1970s did not refer to the use of growth chambers for photosynthesis measurement (Lan-
\end{abstract} ghans, 1978; Tibbitts and Kozlowski, 1979).

Methods used to measure photosynthesis in canopies are similar to those used in single-leaf, gas-exchange systems, and it is useful to understand these principles before scaling-up to canopies. Singleleaf, gas-exchange techniques, devices, construction details, calibrations, and calculations have been reviewed in several recent articles (Field and Mooney, 1990a, 1990b; Field et al., 1989; Parkinson and Day, 1990). McCree (1986) described a system for whole-plant gas exchange in the laboratory; canopy systems for the field were reviewed by Garcia et al. (1990) and Reicosky (1990).

Apparent biological responses in gas-exchange systems are often caused by changes in instrument calibration and electronic noise (which will be discussed later). Thus, it is necessary to fully understand both instrument and organism responses. Gas-exchange components must be calculated from several simultaneous measurements, and it is imperative to understand the instrumentation from which these measures and components are derived. Several books provide a solid background in measurement fundamentals related to gas exchange (Coombs et al., 1985; Goel and Norman, 1990; Hashimoto et al., 1990; Marshall and Woodward, 1985; Pearcy et al., 1989).

This paper describes the use of a commercial growth chamber for canopy photosynthesis, respiration, and transpiration measurements. The system was designed to measure transpiration via water vapor fluxes, and the importance of this measurement is discussed. Procedures for continuous measurement of root-zone respiration are described, and new data is presented to dispel myths about sources of water vapor interference in photosynthesis and in the measurement of $\mathrm{CO}_{2}$ by infrared gas analysis. Mitchell (1992) has described the fundamentals of various approaches to measuring photosynthesis. Because our system evolved from experience with other types of single-leaf and canopy gas-exchange systems, it is useful to review advantages and disadvantages of different systems as they apply to various research objectives.

\section{Closed systems}

Closed systems require the least instrumentation but cannot be used to measure steady-state photosynthesis. The $\mathrm{CO}_{2}$ concentration

\footnotetext{
Received for publication 22 July 1991. This research was supported by National Aeronautics and Space Administration Cooperative Agreement no. NCC 2-139. administered through the Ames Research Center. Moffett Field. Calif., and by the Utah Agricultural Experiment Station. Approved as journal paper no. 4137. I deeply appreciate the dedicated assistance of two graduate students, Oscar Monje and David Meek, who have spent many long hours separating instrument and organism responses in this system. I also thank David Smart, Keith Mott, Ray Wheeler, and Dayle McDermitt for their helpful review comments. The cost of publishing this paper was defrayed in part by the payment of page charges. Under postal regulations, this paper therefore must be hereby marked advertisement solely to indicate this fact.
}

inside the chamber changes rapidly after closure, so that long-term measurements are not possible. Nonetheless, when portability and rapid measurement are important, the advantages of simplicity can outweigh this disadvantage. McDermitt et al. (1989) determined photosynthesis-intercellular $\mathrm{CO}_{2}\left(\mathrm{~A} / \mathrm{C}_{\mathrm{i}}\right)$ curves with a closed single-leaf photosynthesis system (LI-COR model 6200; LI-COR, Lincoln, Neb.) that were nearly identical to those determined with a steady-state system, when corrections were made for gas leakage in the closed system. Closed systems have been used for rapid canopy measurements in the field by quickly lowering a transparent chamber over a canopy and making measurements within a few minutes (Garrity et al., 1984; Meyer et al., 1987). Reicosky (1990) reviewed this approach and discussed its advantages and limitations.

An important disadvantage of closed systems is that perfect closure is impossible, and leaks cause measurement errors because gas leakage brings in an unknown amount of $\mathrm{CO}_{2}$. This influx of $\mathrm{CO}_{2}$ can be insignificant when the total $\mathrm{CO}_{2}$ flux is large (high light, large plants or leaves), but it often is important to accurately measure the small $\mathrm{CO}_{2}$ fluxes associated with dark respiration, low light, low $\mathrm{CO}_{2}$, or small plants. The best approach is to measure and then mathematically correct for leakage. Carbon exchange from leaks, however, varies with chamber tightness, the internal/external $\mathrm{CO}_{2}$ concentration gradient, and the air pressure gradient. The $\mathrm{CO}_{2}$ concentration inside buildings is notoriously erratic because of human activity, and seemingly small changes in air movement and temperature $(\mathrm{PV}=\mathrm{nRT})$ inside and outside the chamber can change the pressure gradient significantly. Two recent papers introduce calibration techniques to minimize the errors associated with leaks (Acock and Acock, 1989; Kimball, 1990).

\section{Semiclosed systems}

Semiclosed systems measure and replace the $\mathrm{CO}_{2}$ removed by photosynthesis. If temperature and humidity are controlled in the chamber, a near steady-state environment can be maintained (Acock et al., 1989; Field et al., 1989; Mitchell, 1992; Wheeler, 1992). Water vapor typically is removed by condensation on a cooling coil, and the increase in $\mathrm{O}_{2}$ concentration from photosynthesis is insignificant unless the chamber is very well sealed. For example, an $\mathrm{O}_{2}$ concentration of $21.9 \%$ inside the chamber is $10,000 \mu \mathrm{mol} \cdot \mathrm{mol}^{-1}$ higher than outside. This large concentration gradient normally drives the $\mathrm{O}_{2}$ out of the chamber by leakage and diffusion.

Semiclosed systems still do not solve the problem of leakage, and plant growth can be affected by gasses released from construction materials (Knight, 1992). In addition, some studies require the simultaneous, real-time measurement of transpiration via water vapor efflux and photosynthesis via $\mathrm{CO}_{2}$ influx. Condensation must be completely prevented to measure water vapor fluxes. The only way to prevent condensation is to remove water vapor from the chamber before it condenses. This requires a large air flow through the chamber, and this approach is called an open system. Large air flows cause other problems, so it is useful to examine the need for measurement of water fluxes before building a system to prevent condensation.

(It is possible to get average transpiration measurements from the volume of condensate, but condensation rate depends on the cooling cycles of the temperature-control system, so the integration interval can be $1 \mathrm{~h}$ or longer).

\section{Incentive for simultaneous measurement of $\mathrm{H}_{2} \mathrm{O}$ and $\mathrm{CO}_{2}$ fluxes}

Water loss and $\mathrm{C}$ gain are fundamentally linked because $\mathrm{H}_{2} \mathrm{O}$ and $\mathrm{CO}_{2}$ diffuse along the same route between the leaf and the air. 
Water-use efficiency (the amount of water lost per $\mathrm{CO}_{2}$ assimilated) can be measured over short intervals $(<1 \mathrm{~min})$ only by simultaneously measuring both gasses. In addition to determining the $\mathrm{C}$ gain/water loss compromise, water vapor must be measured to determine the concentration of $\mathrm{CO}_{2}$ inside the leaf (intercellular $\mathrm{CO}_{2}$ or $\mathrm{C}_{\mathrm{j}}$. This knowledge can then be used to separate biochemical processes from those related to stomatal limitations to photosynthesis. It is nearly impossible to determine stomatal regulation of the exchange of these two gasses unless both gasses are measured simultaneously. Simultaneous measurement of $\mathrm{CO}_{2}$ and $\mathrm{H}_{2} \mathrm{O}$ in single-leaf studies is so valuable that the two gasses are virtually always measured together, and stomatal regulation is the focus of much single-leaf, gas-exchange research.

It is difficult to avoid condensation in canopy gas-exchange systems because a cold surface area is required to remove the large energy input from the lighting system and because canopies lose more water per unit $\mathrm{C}$ gained than single leaves. In spite of the difficulties, investigators have assiduously tried to prevent condensation because they thought $\mathrm{CO}_{2}$ solubility in liquid water would significantly change photosynthesis measurements (see Field et al., 1989, p. 228; Long and Hallgren, 1985, p. 83). However, we now realize that condensation in the chamber or the associated tubing does not significantly affect the accuracy of $\mathrm{CO}_{2}$ flux measurements.

How important is the simultaneous measurement of $\mathrm{CO}_{2}$ and water vapor in canopy studies? Because it is more difficult and more expensive to measure canopy gas exchange than to make the same measurements on single leaves, canopy studies usually include fewer measurements. Models are thus needed to scale-up from relatively well-characterized, single-leaf responses to more complex canopy responses. Characterizing the movement of both $\mathrm{CO}_{2}$ and water vapor in canopies will help to verify these models and increase our understanding of canopy-level processes.

Scaling-up the results of single-leaf studies is not straightforward. For example, a calculated value for $\mathrm{C}_{\mathrm{i}}$ in canopies represents an average of all leaves, which are at different light levels and different vapor pressure gradients. Nonetheless, the canopy response is often similar to that of a big, thick leaf, and $\mathrm{C}_{\mathrm{i}}$ values can be useful in evaluating canopy physiology. We now know that single-leaf measurements also can average dissimilar areas of the leaf. Stomates sometimes do not open uniformly across small areas of leaves (patchy stomatal closure) (Daley et al., 1989; Terashima et al., 1988), and there can be significant differences in temperature and water status of different parts of a leaf (Hashimoto et al., 1984), so averaging diverse responses is not unique to canopies.

Many canopy-level objectives do not require the measurement of $\mathrm{H}_{2} \mathrm{O}$ fluxes. Plant growth rates can be accurately predicted from C fluxes (Dutton et al., 1988), and $\mathrm{H}_{2} 0$ fluxes are not needed to determine C-use efficiency. Respiratory efficiency may be more limiting to yield than photosynthetic or water-use efficiency (Amthor, 1989).

\section{Open systems}

Open systems are widely used for single-leaf gas exchange. They operate in steady-state conditions and solve the problems associated with leaks by pumping enough air through the system to slightly pressurize the chamber, ensuring that all leaks are in one direction (outward). These are significant advantages of open systems, but removing water vapor from a canopy system is far more difficult than from a single-leaf system. Single-leaf systems require an air flow of only a few liters of air per minute to remove water vapor; canopy systems can require 3 orders of magnitude more air to remove water vapor (> 1000 liters of air/minute per square meter of canopy ground area!). This volume of air can be easily produced with a rotary vane blower, but the levels of $\mathrm{CO}_{2}$ and $\mathrm{H}_{2} \mathrm{O}$ in the atmosphere are highly variable (Fig. 1), and this causes apparent fluctuations in gas-exchange rates. Kimball (1990) summarized research concerning short-term atmospheric $\mathrm{CO}_{2}$ fluctuations to demonstrate problems caused by chamber leaks. In an open system, gradual atmospheric $\mathrm{CO}_{2}$ changes are less serious than short-term spikes (1 to $10 \mathrm{~min}$ ) because photosynthesis is calculated from the

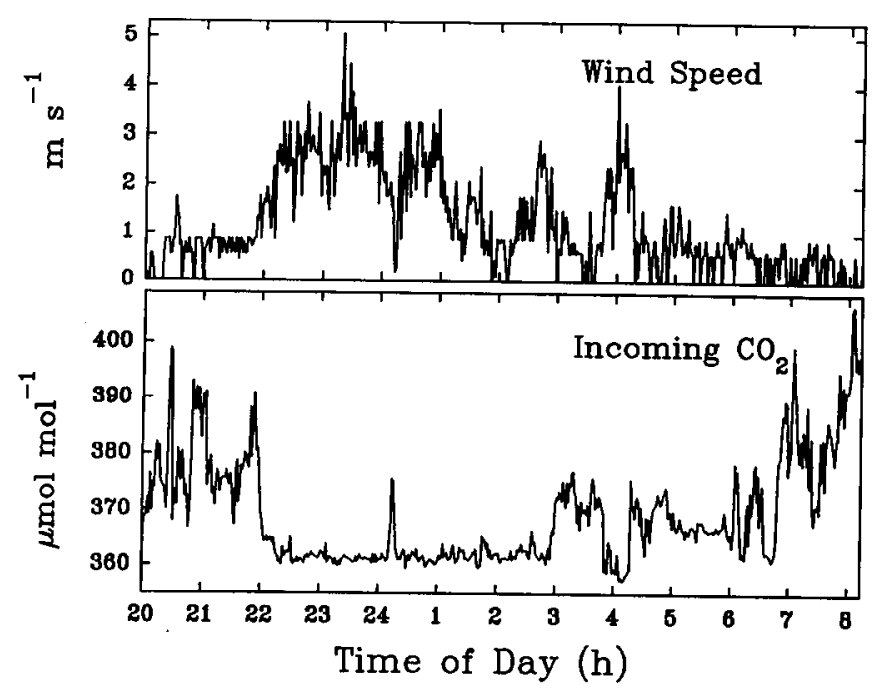

Fig. 1. The relationship between wind speed and $\mathrm{CO}_{2}$ concentration of incoming air. The "spikes" of $\mathrm{CO}_{2}$ in this figure are smaller than those in the atmosphere because the incoming air was buffered by $80 \mathrm{~m}$ of pipe before and after the blower. This data was collected in the winter when the $\mathrm{CO}_{2}$ concentration of the air is elevated from the combustion required to heat buildings. The atmospheric $\mathrm{CO}_{2}$ concentration is lower and less erratic in the summer months. Our laboratory is not located near heavy automobile traffic so the $\mathrm{CO}_{2}$ emissions from automobiles have an insignificant effect on atmospheric $\mathrm{CO}_{2}$.

difference between pre- and postchamber $\mathrm{CO}_{2}$ concentration, and the difference stays constant if the $\mathrm{CO}_{2}$ in the atmosphere changes slowly. It is difficult to buffer the $\mathrm{CO}_{2}$ concentration in large flows of air and the difficulty increases with increasing air flow. A compromise would be to operate an open system with just enough air flow to pressurize the chamber. This could be called a semi-open system.

\section{Semi-open, pressurized system}

Reduced air flows are desirable because they substantially reduce the cost of the gas-buffering system. A small air flow will pressurize a well-sealed chamber but will not remove transpired water vapor, which condenses on cold surfaces. It is thus impossible to measure transpiration via water vapor efflux, but this does not affect $\mathrm{CO}_{2}$ flux measurements. Errors caused by leaks are eliminated by providing sufficient air flow to maintain a positive pressure. The growth chamber described herein can be pressurized with an air flow of 60 liters. $\mathrm{min}^{-1}$, but much higher flow rates (1200 liters. $\mathrm{min}^{-1}$ ) are required to eliminate condensation (i.e., open system mode). Low flow rates can result in a large prechamber/postchamber $\mathrm{CO}_{2}$ gradient $\left(<500 \mu \mathrm{mol} \cdot \mathrm{mol}^{-1}\right)$, but this $\mathrm{CO}_{2}$ difference can be accurately measured with a properly calibrated infrared gas analyzer (IRGA) in the differential mode. Large differences in $\mathrm{CO}_{2}$ concentration can also be measured with a single IRGA in the absolute mode when a three-way switching solenoid is provided; however, we have found that measurements made in differential mode are more reliable. The $\mathrm{CO}_{2}$ concentration in the chamber can be maintained by controlled addition of $\mathrm{CO}_{2}$ to the incoming air stream. Average transpiration rates can still be measured by summing condensate volume and water vapor efflux. We have found this to be the approach of choice when transpiration measurements are less important than $\mathrm{C}$ fluxes.

\section{Choosing among systems}

Closed, semiclosed, and open systems all are accurate when used correctly. Selection of the best system depends on the research objectives. Closed or semiclosed systems facilitate the measurement of volatiles (Wheeler, 1992), require less instrumentation, and are more portable than open systems (Reicosky, 1990). Is it important to make continuous, steady-state measurements? What type of chambers are available and how well can they be sealed? (Most investigators develop a system to best accommodate the chamber). 
What size, type, and amount of plant material must be measured? What will the budget allow? Should the system accommodate future research projects? Can one of the commercially available photosynthesis systems (ADC or LI-COR) be modified for use with an available chamber (see Garcia et al., 1990)? Some of these questions are discussed in other papers (Field and Mooney, 1990a, 1990b; Field et al., 1989; Garcia et al., 1990; Parkinson and Day, 1990).

\section{THE UTAH STATE UNIV. SYSTEM}

The system that my students and I have developed is an open system that evolved in response to research needs and continues to evolve as we find new ways to improve measurements. We are continuously modifying the system, which includes the three subsystems shown in Fig. 2. The system does not condense water, so transpiration and photosynthesis can be measured simultaneously, and stomatal limitations can be evaluated.

\section{The gas-mixing system}

Calculating required flow rates. We found that it is necessary to predetermine the maximum flow rate to purchase appropriately sized blowers, mass-flow meters, and other gas-mixing equipment. The flow rate required to prevent condensation is determined by the water vapor flux from transpiration. Maximum water vapor efflux usually occurs when all incoming shortwave radiation is converted from sensible to latent heat through transpiration. (When leaf temperature is lower than air temperature, however, the latent heat efflux exceeds the sensible heat influx). The energy input from lamp radiation can be measured or accurately estimated for most growth chambers from measurements of photosynthetic photon flux (PPF) and the radiation data presented in Bubenheim et al. (1988). The latent heat of evaporation of water is $2.45 \mathrm{~kJ} \cdot \mathrm{g}^{-1}$ if the leaf and water are at $25 \mathrm{C}$. A shortwave radiation input of $500 \mathrm{~W} \cdot \mathrm{m}^{-2}(0.5$ $\left.\mathrm{kJ} \cdot \mathrm{m}^{-2} \cdot \mathrm{s}^{-1}\right)$ could result in a water vapor efflux of $200 \mathrm{mg} \cdot \mathrm{m}^{-2} \cdot \mathrm{s}^{-1}$ if all energy was used to evaporate water. The water-holding capacity of air depends on temperature (and humidity) and can be calculated from a psychrometric chart or water vapor tables. Air at
$25 \mathrm{C}$ holds $\approx 7 \mathrm{~g} \cdot \mathrm{m}^{-3}\left(7 \mathrm{mg} \cdot \mathrm{liter}^{-1}\right)$ of water between $40 \%$ and $70 \%$ relative humidity, so a flow rate of 28.6 liters $\cdot \mathrm{s}^{-1} \cdot \mathrm{m}^{-2}$ surface area (200 $\mathrm{mg} \cdot \mathrm{m}^{-2} \cdot \mathrm{s}^{-1} / 7 \mathrm{~g} \cdot \mathrm{m}^{-3} ; \approx 60 \mathrm{ft}^{3}$ per min per $\mathrm{m}^{2}$ of surface area) of $25 \mathrm{C}$ air would be required to keep the chamber humidity at $70 \%$. Similar calculations are given in Garcia et al. (1990).

The continuous input of water vapor from transpiration means that the leaf/air vapor pressure gradient can be controlled by controlling the flow rate into the chamber (i.e., humidity is controlled by dehumidification only, and supplemental humidification systems are not needed).

Air can be moved with fans, blowers, or compressors. We use a rotary vane blower to provide a relatively large volume of air at relatively low pressure $(70 \mathrm{kPa})$. Air compressors produce high pressures but an inadequate volume of air. Fans move high air volumes but can develop a pressure of only $\approx 1 \mathrm{kPa}$, which precludes the use of most filters or long pipes. We use $25-\mu \mathrm{m}$ filters before and after the compressor to remove dust.

Buffering the input air. Because the atmospheric concentration of $\mathrm{CO}_{2}$ and water vapor varies (except on windy days; Fig. 1), short-term spikes of these gasses must be buffered to minimize "noise" in the system. We located the system intake as far from the building and as high up as possible, but the air composition was still erratic, so we bubble the air through a $\mathrm{pH}$-buffered solution (1 $\mathrm{mM} \mathrm{Na}_{2} \mathrm{HPO}_{4}$; higher salt concentrations reduce $\mathrm{CO}_{2}$ solubility) to stabilize the $\mathrm{CO}_{2}$ concentration (Fig. 2). We initially tried to buffer $\mathrm{CO}_{2}$ with molecular sieves, but they did not desorb fast enough to be useful. We cool the $\mathrm{pH}$-buffered solution to $1 \mathrm{C}$ to minimize humidification of the incoming air (the cooler solution is also a better $\mathrm{CO}_{2}$ buffer because $\mathrm{CO}_{2}$ solubility is increased). The greater the moisture content of the incoming air, the higher the flow rate required to prevent condensation. Even with the $\mathrm{CO}_{2}$ buffering solution cooled there is still variation in moisture content. A desiccant (calcium aluminosilicate clay) is used to stabilize water vapor concentration. This desiccant is not removed or dried, but is retained in place to maintain a stable, average, water vapor concentration. The desiccant almost completely removes incoming water vapor fluctuations.

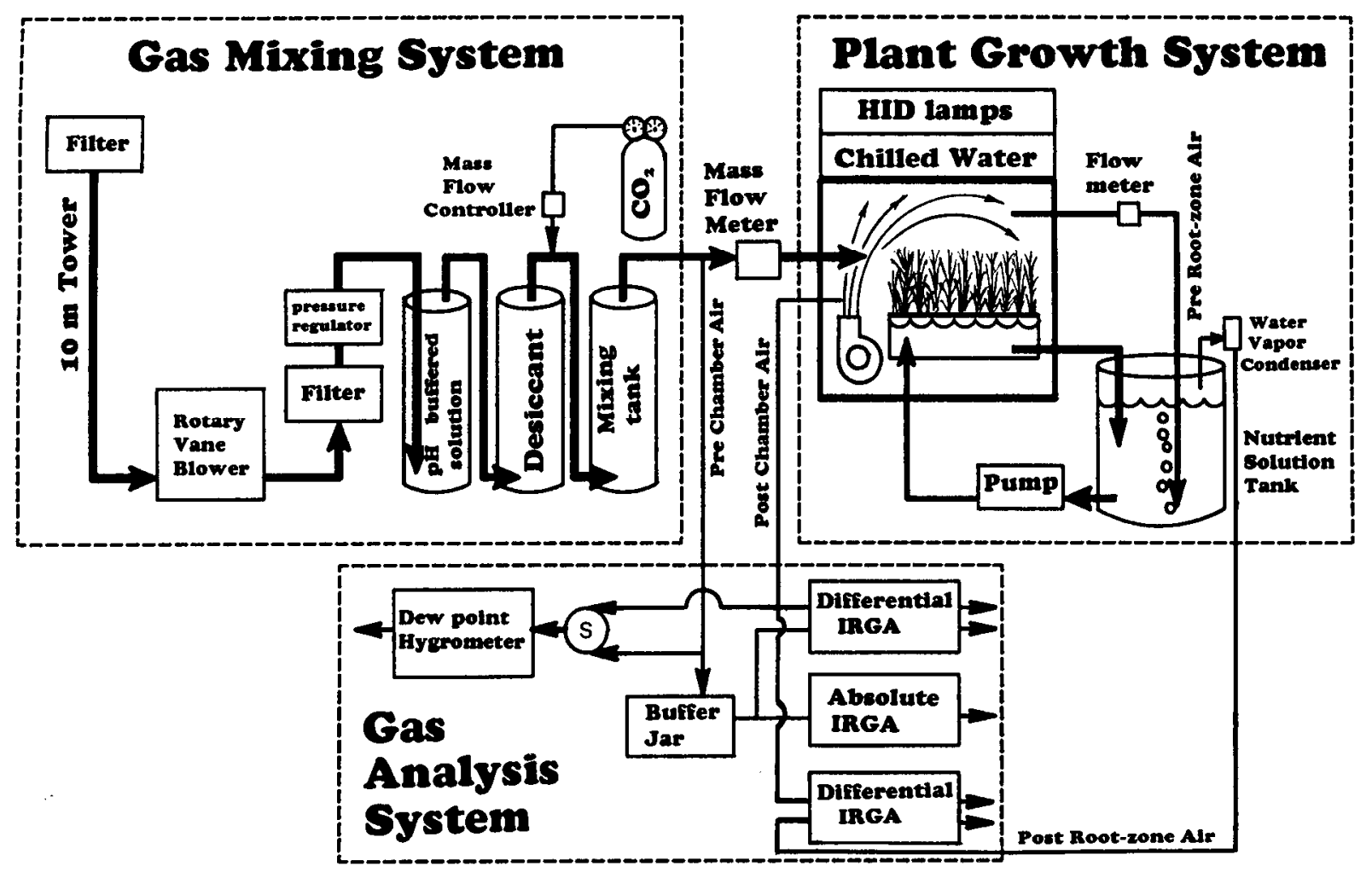

Fig. 2. Schematic diagram of the gas-exchange system. The gas-mixing subsystem provides an air supply with nearly constant $\mathrm{CO}_{2}$ and water vapor concentrations (see discussion in text). The plant growth system was developed by modifying a commercial growth chamber (Environmental Growth Chambers, model EGC-13). The modifications included sealing for leaks, installing larger fans for internal air circulation, and water cooling. The gasanalysis system includes three infrared gas analyzers and a dewpoint hygrometer. 
Pure $\mathrm{CO}_{2}$ from a compressed-gas cylinder is added with a massflow controller after the desiccant cylinder. The $\mathrm{CO}_{2}$ is humidified and filtered through potassium permanganate (Air Repair) to remove contaminants (Morison and Gifford, 1984). (Humidifying the compressed $\mathrm{CO}_{2}$ increases the ability of the potassium permanganate to remove contaminants). The mass-flow controller can be used to maintain a constant prechamber $\mathrm{CO}_{2}$ concentration if the set point is higher than peak spikes of $\mathrm{CO}_{2}$ from the atmosphere (usually $\approx 400 \mu \mathrm{mol} \cdot \mathrm{mol}^{-1}$ ), and if a separate IRGA can be dedicated to monitor and control the input air stream. An empty mixing tank ensures that the injected $\mathrm{CO}_{2}$ is well mixed with the air. A small sample of the input air $\left(0.5\right.$ liter $\left.\cdot \mathrm{min}^{-1}\right)$ goes to the gas analysis system and the remainder is measured with a mass-flow meter immediately before entering the chamber (Fig. 2).

\section{The plant growth system}

Sealing and pressurizing the chamber. Although "open" systems do not need to be as tightly sealed as closed and semiclosed systems, they must be tight enough to be slightly pressurized so that all leaks are from inside to outside. The internal pressure need only be 10 $\mathrm{Pa}$ (1 mm water column), just enough to be measurable, but pressure must be positive in all parts of the chamber. In most growth chambers, fans pull internal air through a heat exchanger so that pressure in the fan plenum will be much lower than that in the rest of the chamber. This pressure difference often is 200 to $400 \mathrm{kPa}$. We use a manometer filled with red, low-specific-weight oil (red gauge oil) to monitor pressure in the fan plenum. Although the area around the fans is particularly well sealed, we detect $\mathrm{CO}_{2}$ exchange if the pressure is slightly negative $(-10 \mathrm{~Pa} ;-1 \mathrm{~mm}$ water column); the $\mathrm{CO}_{2}$ exchange is eliminated if the pressure is slightly positive $(+10$ $\mathrm{Pa} ;+1 \mathrm{~mm}$ water column), which illustrates the importance of positive pressure.

The leak rate increases in direct proportion to the pressure gradient (Ohms Law; flux = driving gradient/resistance, or leak rate $=$ pressure gradient/chamber resistance to leaks). Small internal pressure gradients make it possible to maintain the chamber at a uniformly low positive pressure. Minimizing the resistance to air flow in the duct system and heat exchanger will minimize internal pressure gradients and leaks, which, in turn, will reduce input air requirements to maintain a positive pressure.

Our chamber can be pressurized with an input air flow rate of 1 liter $\cdot \mathrm{s}^{-1}\left(3600\right.$ liters $\left.\cdot \mathrm{h}^{-1}\right)$. This air flow keeps the fan chamber at 10 -Pa pressure (pressure in the plant growth section is $\approx 200 \mathrm{~Pa}$ because of resistance in the heat exchanger). We sealed and tested for leaks several times before we were satisfied with chamber tightness. The biggest leak, which occurred around the seal of the door, was minimized with closed-cell foam and a screw clamp to close the door. It was necessary to seal pop-rivets and all seams with silicone sealant. We typically add between 3 and 20 liters of air per second to the chamber, which means that the chamber is more tightly sealed than is required for most studies. A well-sealed chamber, however, allows more accurate measurement of small gas fluxes, such as $\mathrm{C}$ efflux resulting from seed germination. At high-input flow rates, vents must be opened to avoid excessive pressure buildup.

Rapid internal air mixing. The composition of the air in open chambers must be relatively uniform so that air sampled at one point is representative of the entire chamber (and representative of what is leaking out). This is best accomplished by rapid circulation of internal air, which also improves environmental uniformity and minimizes boundary layers above and within the canopy. Fans were installed to circulate 400 liters of air per second through the chamber, which is 2 to 3 times more air flow than most commercial growth chambers. The incoming air (3 to 20 liters $\cdot s^{-1}$ ) enters through a manifold and almost immediately mixes with the 400 liters $\cdot \mathrm{s}^{-1}$ of internal circulation.

Wind speed at the top of the chamber (below the glass top) is 2 to $3 \mathrm{~m} \cdot \mathrm{s}^{-1}$ but declines to a more acceptable $0.8 \mathrm{~m} \cdot \mathrm{s}^{-1}$ at the top of the plant canopy. The wind speed should be as high as possible without mechanically stressing the plants. We assume that some leaf flutter is desirable, but that excessive stem and leaf bending is undesirable. The effects of air velocity probably are mediated through both hormonal changes (Latimer and Mitchell, 1988) and plant water potential. Wadsworth $(1959,1960)$ found that plant growth was not altered over a range of air velocities from 0.3 to $4.0 \mathrm{~m} \cdot \mathrm{s}^{-1}$ when plants were grown in solution culture. Plants grown in sand culture, however, grew more slowly as air velocity increased. Wadsworth (1960) speculated that differences in plant water potential were responsible for differences in growth because water availability was less in sand culture than in solution culture, and increased air velocity increased water loss by transpiration.

Temperature control: water cooling. Water is the medium of choice for temperature control in almost all growth chambers for two reasons: 1) its high specific heat capacity results in more uniform temperature control over time, and 2) unlike freon, it does not change state (from liquid to gas) as it absorbs energy. Freon causes cold spots and, thus, condensation when it changes state in the heat exchanger; water-cooled heat exchangers are more uniformly cool. Water temperature is controlled in our system by regulating the flow of freon (from a primary refrigeration system) to a chilled water bath. The chilled water then is circulated through a heat exchanger in the chamber and a water heat filter located below the lamps. The circulating water filter removes $\approx 60 \%$ of the lamp radiation (Bubenheim et al., 1988), and the remainder is removed by the chamber heat exchanger. A large heat exchanger was installed in the chamber so that the water is only $\approx 3 \mathrm{C}$ lower than the air. Thus, condensation occurs only when relative humidity exceeds $80 \%$.

Measuring root-zone respiration. If desired, the gas-exchange system can be adapted to separately measure root-zone $\mathrm{CO}_{2}$ efflux. The $\mathrm{CO}_{2}$ concentration in the air above the sealed hydroponic system is measured using the same principles employed to measure $\mathrm{CO}_{2}$ fluxes in the foliar environment. The root zone is pressurized, but the pressure is less than overall chamber pressure, which helps to minimize root-zone $\mathrm{CO}_{2}$ efflux into the chamber. Wheat seeds are direct-seeded into a sheet of expanded rockwool medium (Grodan), which is then sealed to the containers with closed-cell foam. Rapid nutrient solution flow rates $\left(0.4\right.$ liter $\cdot \mathrm{m}^{2}$ of surface area per second) mean that the air above the solution comes to $\mathrm{CO}_{2}$ equilibrium with the solution in a few minutes. Root-zone acidity is maintained at $\mathrm{pH}=4.8$ to minimize dissolved $\mathrm{C}$ in solution (as carbonic acid, bicarbonate, and carbonate), which reduces the magnitude of temperature and $\mathrm{pH}$ effects on $\mathrm{C}$ solubility. We tested the accuracy and response time of the system to $\mathrm{CO}_{2}$ fluxes by adding measured amounts of sodium bicarbonate to the solution in the chamber under conditions of controlled $\mathrm{pH}$ and temperature. At least $95 \%$ of the $\mathrm{C}$ originally in bicarbonate was recovered as $\mathrm{CO}_{2}$ in the root-zone gas analyzer (2\% to $3 \%$ of the $\mathrm{CO}_{2}$ leaked into the foliar environment and was measured by another analyzer). The response time and $\mathrm{CO}_{2}$ recovery were not significantly improved by maintaining the solution at $\mathrm{pH} 4$. Results of these tests also helped quantify $\mathrm{CO}_{2}$ leakage from the root zone into the foliar environment. Details of the design and operation of the recirculating hydroponic system have been published (Bugbee and Salisbury, 1988, 1989). Figure 3 illustrates the diurnal cycle of root respiration and photosynthetic rate of the foliar environment.

\section{The gas analysis system}

A three-way solenoid valve is used to intermittently cycle preand post-chamber air to a single dewpoint hygrometer (Fig. 2). A single IRGA in absolute mode could be used with this same solenoid, but an IRGA in the differential mode can more accurately measure small $\mathrm{CO}_{2}$ differences in the pre/postchamber air.

The plant growth chamber (1700-liter volume) helps to stabilize the $\mathrm{CO}_{2}$ concentration of the postchamber air, but this reduces "noise" only if the prechamber air is equivalently buffered. The prechamber air can be buffered with a small Erlenmeyer flask because only the small gas flow rate into the IRGA $\left(\approx 0.5\right.$ liters $\left.\cdot \mathrm{min}^{-1}\right)$ must be buffered. The size of the flask and the flow rate into the IRGA must be selected to match the buffering capacity provided by the chamber. For example, if the chamber input flow rate were 800 liters $\cdot \min ^{-1}$, the chamber would provide a buffering ratio of 2.125 


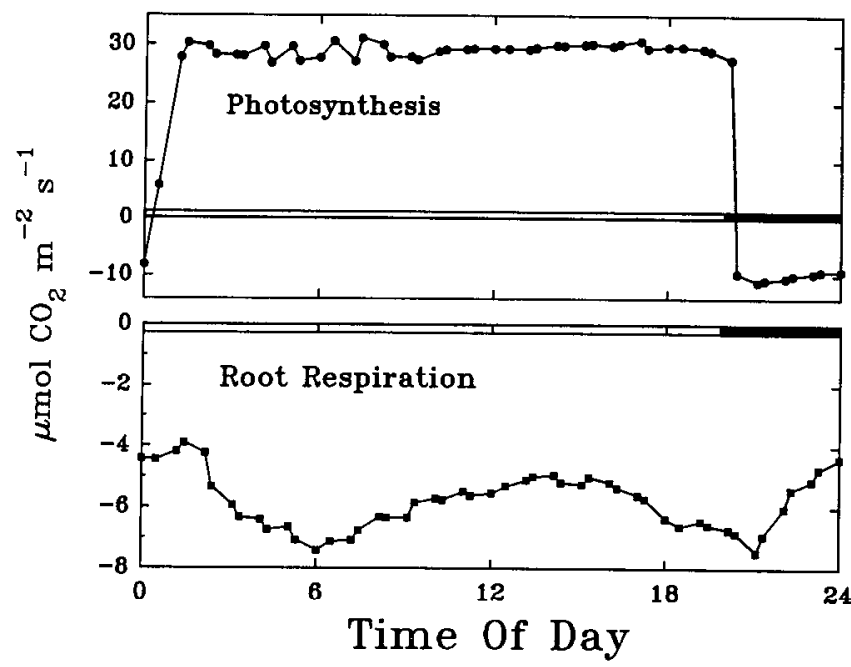

Fig. 3. A 24-h cycle of shoot and root $\mathrm{CO}_{2}$ fluxes. There was an abrupt change from the light period to the dark period after $20 \mathrm{~h}$. Root respiration typically increases within a few hours after the lights come on and decreases a few hours after the lights go off. The symbols represent 30 -min averages.

(1700/800). A 1-liter flask has the same buffering capacity if the flow rate into the IRGA is 0.471 liter $\cdot \min ^{-1}(1 / 2.125=0.471)$. The flask is represented by the box labeled "buffering jar" in Fig. 2.

\section{The data acquisition system}

Data acquisition is really a fourth subsystem (not shown in Fig. 2 ), which quickly becomes essential as the system gets more complex. Data acquisition systems save labor, money, and improve measurement capability; because they can process signals from several types of sensors, it is not necessary to purchase separate meters for each sensor. For example, the sensor for our dewpoint hygrometer (General Eastern, model DEW-10) cost about \$800; a standalone dewpoint hygrometer can cost well over \$2000. Data acquisition systems digitize and linearize signals more accurately than the analog linearization provided with most sensors. Redundant analog linearization devices on each sensor are not needed. Real-time computer graphics are immensely useful because they immediately indicate erratic values, which, in turn, indicate the need for calibration, or incipient equipment failure. Data acquisition systems also automate data collection, a prerequisite to long-term studies.

Choosing among data acquisition systems is a complicated task, particularly for biologists. Pearcy (1989) discusses data acquisition systems and includes a table comparing data logger and data acquisition system characteristics. We use a data logger from Campbell Scientific (model CR-10) because it can be expanded to include enough input channels for gas-exchange systems (expandable in 32channel increments) and it is much less expensive than larger data acquisition systems. The measurement resolution of Campbell Scientific data loggers is also better than most of the larger data acquisition systems [see Table 2.1 in Pearcy (1989)]. Because new data logger models are continually being introduced, it is useful to get updated information from the manufacturers before making a decision about suitability.

Electronic signals and calibration. Despite their assets, data loggers have some disadvantages. Measurements become more abstract, which tends to "distance" the investigator from the organism of interest. A researcher must develop the ability to distinguish between instrument-induced responses (i.e., artifacts) and biological responses. This ability requires a knowledge of both the instruments and the organism. Unusual results almost always are the result of bad calibration, electronic interference, or a failure of the environmental control systems (but sometimes the unusual results are fascinating physiological responses!). Gas exchange has great potential, but as with any evolving technology, there also are many pitfalls. Changes in the laboratory temperature can alter instrument calibration. Bloom (1989) offers a good discussion of instrumentation errors in gas-exchange systems. Leuning and Sands (1989) discuss calibration of a closed system (LI-COR model 6200). Other authors have emphasized the need to simultaneously test all components of gas-exchange systems [i.e., measuring fluxes of zero in an empty chamber (Field et al., 1989; Tranquillini and Caldwell, 1972)].

\section{Some representative results}

After canopy closure, photosynthesis usually is a linear function of PPF if $\mathrm{CO}_{2}$ is elevated (Fig. 4). Stomates, however, do not appear to completely close in darkness (in hydroponic culture) and are almost as open at half full sunlight as at full sunlight (full sunlight $=2000 \mu \mathrm{mol} \cdot \mathrm{m}^{-2} \cdot \mathrm{s}^{-} ;$; Fig. 4).

As expected, the average stomatal conductance decreases as the concentration of $\mathrm{CO}_{2}$ increases, but there is little additional effect of $\mathrm{CO}_{2}$ on stomates after $\approx 1000 \mu \mathrm{mol} \cdot \mathrm{mol}^{-1}$ (Fig. 5). We have found, however, that short-term canopy photosynthesis is not saturated at a $\mathrm{CO}_{2}$ level of $1000 \mu \mathrm{mol} \cdot \mathrm{mol}^{-1}$.

The rate of canopy photosynthesis as a function of the average intercellular $\mathrm{CO}_{2}$ of all the leaves (a canopy $\mathrm{A} / \mathrm{C}_{\mathrm{i}}$ curve) is compared with that for ambient $\mathrm{CO}_{2}$ in Fig. 6. These measurements were made 25 days after seedling emergence, when the canopy was growing rapidly. The initial slope of the curve is steep, suggesting high Rubisco activity in the leaves (Farquhar and Sharkey, 1982). We are currently interested in making this measurement at different stages of the life cycle to determine ontogenic changes in the canopy biochemical capacity to conduct photosynthesis.

Short-term environmental effects on photosynthesis often differ from long-term effects. For example, the increased growth rate associated with high temperature, high PPF, and high $\mathrm{CO}_{2}$ levels is higher over a few days than over a few weeks (Bugbee, 1992).

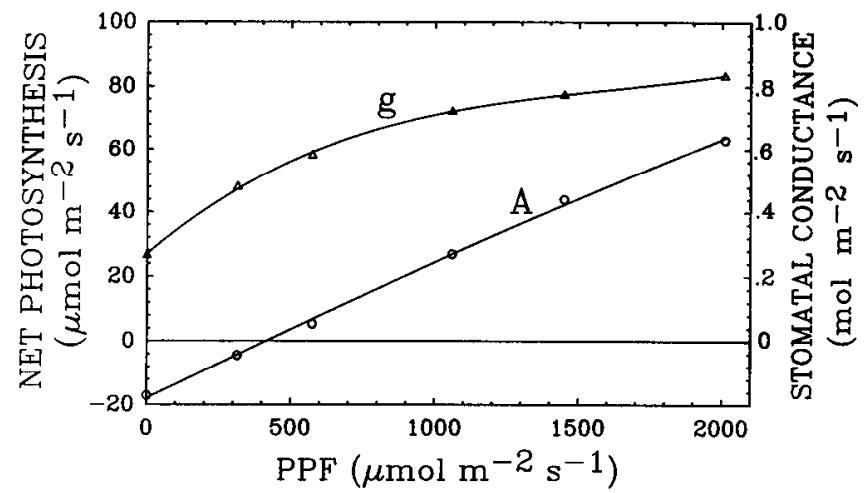

Fig. 4. The effect of PPF on canopy net photosynthesis (assimilation, A) and stomatal conductance ( $\mathrm{g}$ ) in a fully developed wheat canopy. The $\mathrm{CO}_{2}$ concentration was $1000 \mu \mathrm{mol} \cdot \mathrm{mol}^{-1}$ at all PPF levels.

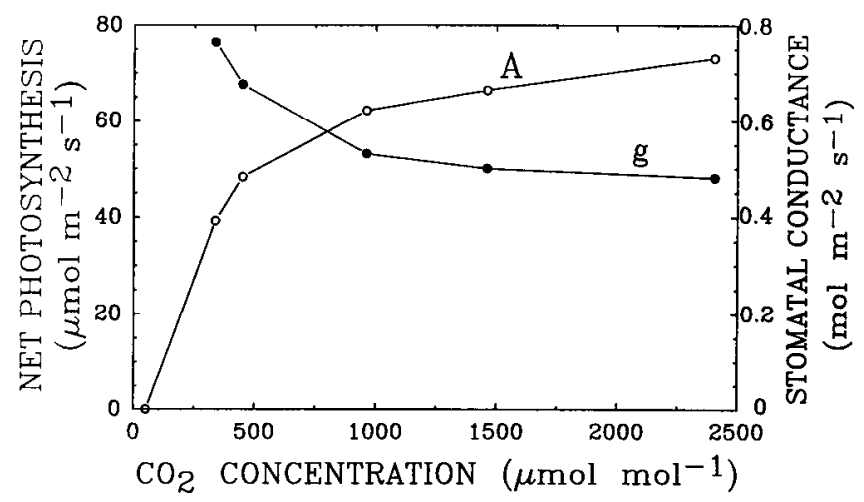

Fig. 5. The effect of $\mathrm{CO}_{2}$ concentration on canopy net photosynthesis (assimilation, $\mathrm{A}$ ) and stomatal conductance $(\mathrm{g})$ in a fully developed wheat canopy. PPF was $2000 \mu \mathrm{mol} \cdot \mathrm{m}^{-2} \cdot \mathrm{s}^{-1}$ at all $\mathrm{CO}_{2}$ levels. 


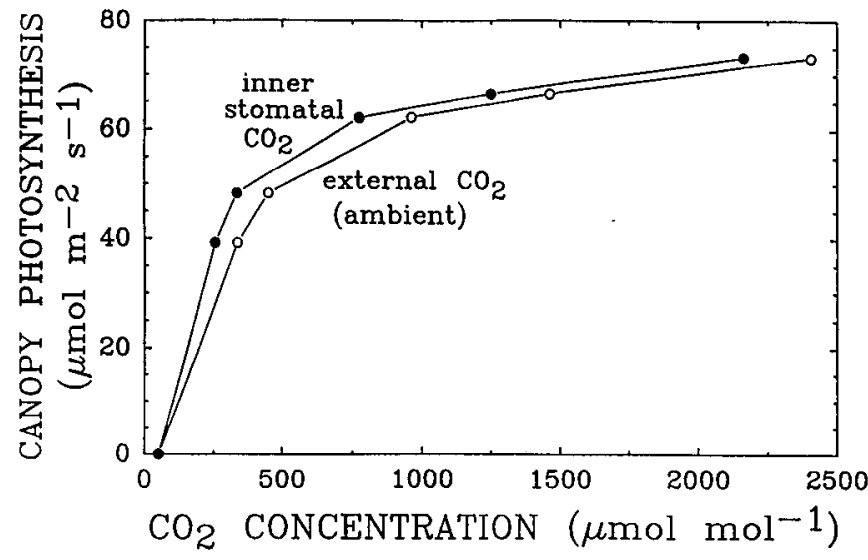

Fig. 6. The effect of intercellular $\mathrm{CO}_{2}$ and external (ambient) $\mathrm{CO}_{2}$ concentrations on the photosynthetic rate of a young, fully developed wheat canopy. The data are calculated from the data in Fig. 5.

Many models of crop growth are based on the hypothesis that canopies respond in the same way as large, thick leaves, i.e., canopies respond on a ground area basis just as leaves respond on a leaf surface area basis. Our data do not support this hypothesis for photosynthetic response to temperature and radiation intensity, but photosynthetic response curves for $\mathrm{CO}_{2}$ are similar to response curves for single leaves (Meek, 1990).

In a preliminary study, we predicted final plant dry biomass to within $97 \%$ by integrating measurements of $C$ fluxes. This finding validates that our measurements of net $\mathrm{CO}_{2}$ have a high degree of accuracy (Dutton et al., 1988).

\section{SOURCES OF WATER VAPOR INTERFERENCE WITH PHOTOSYNTHESIS MEASUREMENTS}

Transpiration produces large fluxes of water vapor. This water vapor must be removed from the chamber with a large air flow to prevent condensation in the coldest parts of the chamber, as previously discussed. Gases quickly go into solution in this condensed water because of rapid air movement over the cooling coil and are then drained out of the chamber with the water. Investigator concern about $\mathrm{CO}_{2}$ losses in condensed water (see Tranquillini and Caldwell, 1972) was emphasized in a widely cited study by Bloom et al. (1980). The calculations used by Bloom et al. to estimate these losses were based on an atmospheric $\mathrm{CO}_{2}$ concentration of $100 \%$. Actual $\mathrm{CO}_{2}$ concentrations in controlled plant environments rarely exceed $0.2 \%\left(2000 \mu \mathrm{mol} \cdot \mathrm{mol}^{-1}\right)$ so $\mathrm{CO}_{2}$ flux into water is several fold less than originally calculated.

In fact, the effect of $\mathrm{CO}_{2}$ solubility on photosynthesis is insignificant. Pure $\mathrm{CO}_{2}$ gas is highly soluble in pure water [36.5 mmol.liter ${ }^{-1}$ at 20C and $1 \mathrm{~atm}$ pressure (Forsythe, 1969; Umbreit et al., 1964)], but at ambient $\mathrm{CO}_{2}$ levels $(0.035 \%)$, its solubility is only 12.8 picomol per liter $\left(36.5 \mathrm{mmol} \cdot \mathrm{liter}^{-1} \times 0.00035\right)$. This means that 0.23 pmol of $\mathrm{CO}_{2}$ goes into solution for each mole of water transpired $\left(12.8 \mathrm{pmol} / 55.6\right.$ moles of $\mathrm{H}_{2} \mathrm{O}$ per liter) if no water leaves the chamber as water vapor (worst case, all water vapor condensed in chamber). The effect of this loss of $\mathrm{CO}_{2}$ on photosynthesis depends on the transpiration : photosynthesis ratio. Assuming a worst case of $10,000 \mathrm{~mol} \mathrm{H}_{2} \mathrm{O}$ transpired per mol $\mathrm{CO}_{2}$ fixed, $2.3 \mu \mathrm{mol} \mathrm{CO}_{2}$ would be lost in solution per mol $\mathrm{CO}_{2}$ fixed in photosynthesis, which is $0.00023 \%$ of the photosynthetic rate $(0.23 \times 10,000=2.3 \mu \mathrm{mol})$. However, $\mathrm{CO}_{2}$ solubility almost doubles when the water temperature decreases to $0 \mathrm{C}$, and the $\mathrm{CO}_{2}$ concentration in growth chambers is often elevated above ambient levels. Both factors can increase the $\mathrm{CO}_{2}$ solubility error, but it would be extremely unusual to have conditions that would increase the error to more than $0.02 \%$ of the photosynthetic rate.

We empirically verified these calculations in a single-leaf system and in our canopy gas-exchange system by creating large amounts of condensation in an empty chamber and measuring the apparent photosynthetic rate. As expected, not enough $\mathrm{CO}_{2}$ was lost to measure an apparent photosynthetic rate. Therefore, it is necessary to avoid condensation in gas-exchange chambers and associated tubing only when measuring transpiration. In spite of this finding, investigators have continued to assume that water interferes with measurement of $\mathrm{CO}_{2}$ fluxes.

The concern over adverse effects of condensation in chambers probably reflects confusion over how water vapor interferes with the measurement of $\mathrm{CO}_{2}$ by infrared gas analyzers. 'Two mechanisms of interference are well known, and the importance of a third interfering mechanism recently has been elucidated.

The most widely recognized interference is from overlapping infrared absorption bands between 2.5 and $3 \mu \mathrm{m}$ (Field et al., 1989; p. 215-217). Gas analyzers manufactured during the past 20 years use optical filters to almost completely eliminate overlapping absorption bands between $\mathrm{CO}_{2}$ and water vapor (Parkinson, 1971). This interference cannot be eliminated completely because water vapor has some absorbance at all infrared wavelengths.

The second source of interference results from dilution of the mole fraction of $\mathrm{CO}_{2}$ by water vapor. Penning de Vries et al. (1984) point out that this source of error was not widely appreciated before the 1980s. Bunce and Ward (1985) examined water vapor interference and concluded that none of the three analyzers that they tested eliminated overlapping absorption bands with water vapor (contrary to manufacturers' claims). It now appears, however, that some of the $\mathrm{H}_{2} \mathrm{O}$ interference reported by Bunce and Ward was caused by a third source of interference, foreign gas band broadening.

Intermolecular collisions in the gas phase alter infrared absorption band widths and intensities, causing infrared gas analyzer calibrations to be pressure-dependent. This phenomenon, variously called band broadening, pressure broadening, or foreign gas broadening, is well described for many gasses, but the principles have only recently been applied to predict the effect of water vapor on $\mathrm{CO}_{2}$ infrared absorbance (LI-COR, 1990). Partial pressures of different gas species influence $\mathrm{CO}_{2}$ infrared absorption to varying degrees; for example, the partial pressure of water vapor has a much greater effect on $\mathrm{CO}_{2}$ infrared absorption than do equal changes in the partial pressures of $\mathrm{O}_{2}$ or $\mathrm{N}^{2}$ (ibid). Investigators have typically attributed the interaction of $\mathrm{CO}_{2}$ and water vapor to incomplete optical filtering (i.e., overlapping absorption bands), but almost all of the effect 'probably was the result of band broadening.

Calibration and subsequent correction for water vapor interference requires simultaneous measurement of water vapor concentration so many investigators dry the air to a constant water vapor concentration before analysis, but drying adds to system complexity. The air can be dried either by cooling to condense the water vapor or by using a desiccant. Most desiccants absorb both $\mathrm{CO}_{2}$ and $\mathrm{H}_{2} \mathrm{O}$. The desiccant of choice is magnesium perchlorate, but even it must be used with caution (Samish, 1978). Desiccants must be replaced at regular intervals, which is inconvenient and expensive in long-term studies (magnesium perchlorate cannot be regenerated). We previously corrected for water vapor interference, but recently installed a chilled water system to condense water vapor to a constant $1 \mathrm{C}$ before $\mathrm{CO}_{2}$ analysis

\section{Literature Cited}

Acock, B. and M. Acock. 1989. Calculating air leakage rates in controlledenvironment chambers containing plants. Agron. J. 81:619-623.

Acock, V., B. Acock, and M. Acock. 1989. Seasonal carbon and nitrogen accumulation in relation to net carbon dioxide exchange in a carbon dioxide-enriched soybean canopy. Agron. J. 81:78-83.

Amthor, J. 1989. Respiration and crop productivity. Springer-Verlag, New York.

Bloom, A.J. 1989. Principles of instrumentation for physiological ecology, p. 1-13. In: R.W. Pearcy, J. Ehleringer, H.A. Mooney, and P.W. Runde (eds.). Plant physiological ecology: Field methods and instrumentation. Chapman and Hall, New York.

Bloom, A., H. Mooney, O. Bjorkman, and J. Berry. 1980. Materials and methods for carbon dioxide analysis. Plant. Cell. \& Environ. 3:371-376.

Bubenheim, D., B. Bugbee, and F: Salisbury 1988. Radiation in controlled environments: Influence of lamp type and filter material. J. Amer. Soc. Hort. Sci. 113:468-474. 
Bugbee, B. 1992. Determining the potential productivity of food crops in controlled environments. Adv. in Space Res. p. 5:85-95.

Bugbee, B. and F. Salisbury. 1988. Exploring the limits of crop productivity: Photosynthetic efficiency in high irradiance environments. Plant Physiol. 88:869-878.

Bugbee, B. and F. Salisbury. 1989. Controlled environment crop production: Hydroponic vs. lunar regolith, p. 107-129. In: D. Henninger and D. Ming (eds.). Lunar base agriculture: Soils for plant growth. Amer. Soc. Agron., Madison, Wis.

Bunce, J.A. and D.A. Ward. 1985. Errors in differential infrared carbon dioxide analysis resulting from water vapor. Photosyn. Res. 6:289-294.

Coombs, J., D. Hall, S. Long, and J. Scurlock. 1985. Techniques in bioproductivity and photosynthesis. Pergamon Press, Oxford, U.K.

Daley, P., K. Raschke, J.T. Ball, and J. Berry. 1989. Topography of photosynthetic activity of leaves obtained from video images of chlorophyll fluorescence. Plant Physiol. 90:1233-1238.

Dutton, R., J. Jiao, M. Tsujita, and B. Grodzinski. 1988. Whole plant CO exchange measurements for nondestructive estimation of growth. Plant Physiol. 86:355-358.

Farquhar, G. and T. Sharkey. 1982. Stomatal conductance and photosynthesis. Annu. Rev. Plant Physiol. 33:317-345.

Field, C.B., J.T. Ball, and J.A. Berry. 1989. Photosynthesis: Principles and field techniques, p. 209-254. In: R.W. Pearcy, J. Ehleringer, H.A Mooney, and P.W. Rundel (eds.). Plant physiological ecology: Field methods and instrumentation. Chapman and Hall, New York.

Field, C. and H. Mooney. 1990a. Measuring photosynthesis under field conditions: Past and present approaches, p. 185-205. In: Y. Hashimoto, P. Kramer, H. Nonami, and B. Strain (eds.). Measurement techniques in plant science. Academic, New York.

Field, C. and H. Mooney. 1990b. Leaf chamber methods for measuring photosynthesis under field conditions, p. 117-137. In: N. Goel and J. Norman (eds.). Instrumentation for studying vegetation canopies for remote sensing in optical and thermal infrared regions. Remote Sensing Revs. vol. 5. Harwood Academic. New York.

Forsythe, W. 1969. Smithsonian physical tables. 9th ed. Smithsonian Institution Press, Washington, D.C.

Garcia, R., J. Norman, and D. McDermitt. 1990. Measurements of canopy gas exchange using an open chamber system, p. 141-162. In: N. Goel and J. Norman (eds.). Instrumentation for studying vegetation canopies for remote sensing in optical and thermal infrared regions. Remote Sensing Revs. vol. 5. Harwood Academic, London.

Garrity, D., C. Sullivan, and D. Watts. 1984. Rapidly determining sorghum canopy photosynthetic rates with a mobile canopy chamber. Agron. J. 76:163-165.

Goel, N.F. and J.M. Norman. 1990. Instrumentation for studying vegetation canopies for remote sensing in optical and thermal infrared regions. Remote Sensing Revs. vol. 5. Harwood Academic, London.

Hashimoto, Y.. P. Kramer. and B. Strain. 1990. Measurement techniques in plant science. Academic, San Diego.

Hashimoto, Y., I. Taketoshi, P. Kramer, A. Naylor, and B. Strain. 1984. Dynamic analysis of water stress in sunflower leaves by means of a thermal image processing system. Plant Physiol. 76:266-269.

Kimball, B. 1990. Exact equations for calculating air leakage rates from plant growth chambers. Agron. J. 82:998-1003.

Knight, S.L. 1992. Constructing specialized plant growth chambers for gasexchange measurements: Considerations and concerns. HortScience 27:767769.

Langhans, R. 1978. A growth chamber manual. Cornell Univ. Press, Ithaca, N.Y.

Latimer, J. and C. Mitchell. 1988. Effects of mechanical stress or abscisic acid on growth, water status, and leaf abscisic acid content of eggplant seedlings. Scientia Hort. 36:37-46.

Leuning, R. and P. Sands. 1989. Theory and practice of a portable photosynthesis instrument. Plant Cell \& Environ. 12:669-678.
LI-COR. 1990. Instruction manual for the $\mathrm{CO}_{2} / \mathrm{H}_{2} \mathrm{O}$ analyzer. LI-COR, Lincoln, Neb.

Long, S. and J. Hallgren. 1985. Measurement of $\mathrm{CO}_{2}$ assimilation by plants in the field and in the laboratory, p. 62-94. In: J. Coombs, D. Hall, S. Long, and J. Scurlock (eds.). Techniques in bioproductivity and photosynthesis. Pergamon Press, New York.

Marshall, B. and F.I. Woodward. 1985. Instrumentation for environmental physiology. Cambridge Univ. Press, New York.

McCree, K.J. 1986. Measuring the whole-plant daily carbon balance. Photosynthetica $20: 82-93$.

McDermitt, D.K., J.M. Norman, J.T. Davis, T.M. Ball, T.J. Arkebauer, J.M. Welles, and S.R. Roemer. 1989. $\mathrm{CO}_{2}$ response curves can be measured with a field-portable closed-loop photosynthesis system. For. Tree Physiol. 46:416-420.

Meek, D. 1990. The relationship between leaf area index and photosynthetic temperature response in wheat canopies. M.S. Thesis, Utah State Univ., Logan.

Meyer, W., D. Reicosky, H. Barrs, and G. Shell. 1987. A portable chamber for measuring canopy gas exchange of crops subject to different root zone conditions. Agron. J. 79:181-184.

Mitchell, C.A. 1992. Measurement of photosynthetic gas exchange in controlled environments. HortScience 27:764-767.

Morison, J. and R. Gifford. 1984. Ethylene contamination of $\mathrm{CO}_{2}$ cylinders. Plant Physiol. 75:275-277.

Parkinson, K.J. 1971. Carbon dioxide infra-red gas analysis. Effects of water vapor. J. Expt. Bot. 22:169-176.

Parkinson, K. and W. Day. 1990. Design and testing of leaf cuvettes for use in measuring photosynthesis and transpiration, p. 207-228. In: Y. Hashimoto, P. Kramer, H. Nonami, and B. Strain (eds.). Measurement techniques in plant science. Academic, New York.

Pearcy, R.W. 1989. Field data acquisition, p. 15-28. In: R.W. Pearcy, J. Ehleringer, H.A. Mooney, and P.W. Rundel (eds.). Plant physiological ecology: Field methods and instrumentation. Chapman and Hall, New York.

Pearcy, R.W., J. Ehleringer, H.A. Mooney, and P.W. Rundel (eds.). 1989. Plant physiological ecology: Field methods and instrumentation. Chapman and Hall, New York.

Penning de Vries, P., J. Akkersdijk, and J. Oorschot. 1984. An error in measuring respiration and photosynthesis due to transpiration. Photosynthetica 18:146-149.

Reicosky, D. 1990. Canopy gas exchange in the field: Closed chambers, p. 163-177. In: N. Goel and J. Norman (eds.). Instrumentation for studying vegetation canopies for remote sensing in optical and thermal infrared regions. Remote Sensing Revs. vol. 5. Harwood Academic, New York.

Samish, Y. 1978. Measurement and control of $\mathrm{CO}_{2}$ concentration in air is influenced by the desiccant. Photosynthetica 12:73-75.

Terashima, I., S.-C. Wong, C. Osmond, and G. Farquhar. 1988. Characterization of nonuniform photosynthesis inducted by abscisic acid in leaves having different mesophyll anatomies. Plant Cell Physiol. 29:385-394.

Tibbitts, T. and T. Kozlowski. 1979. Controlled environment guidelines for plant research. Academic, New York.

Tranquillini, W. and M.M. Caldwell. 1972. Integrating calibrations of plant gas exchange systems. Ecology 53:974-976.

Umbreit, W., R. Burris, and J. Stauffer. 1964. Manometric techniques: A manual describing methods applicable to the study of tissue metabolism. 4th ed. Burgess Publishing Co., Minneapolis.

Wadsworth, R. 1959. An optimum wind speed for plant growth. Ann. Bot. 23:195-199.

Wadsworth, R. 1960. The effect of artificial wind on the growth rate of plants in water culture. Ann. Bot. 24:200-211.

Wheeler, R.M. 1992. Gas-exchange measurements using a large, closed plant growth chamber. HortScience 27:777-780. 